\title{
Production system and material efficiency challenges for large scale introduction of complex materials
}

Martin Kurdve, Fredrik Henriksson, Magnus Wiktorsson, Patrick Denzler, Mats Zachrisson and Marcus Bjelkemyr

The self-archived postprint version of this journal article is available at Linköping University Institutional Repository (DiVA):

http:// urn.kb.se/ resolve?urn=urn:nbn:se:liu:diva-143015

N.B.: When citing this work, cite the original publication.

Kurdve, M., Henriksson, F., Wiktorsson, M., Denzler, P., Zachrisson, M., Bjelkemyr, M., (2017),

Production system and material efficiency challenges for large scale introduction of complex materials, Advanced Materials Proceedings, 2(8), 492-499. https:// doi.org/ 10.5185/ amp.2017/ 805

Original publication available at:

https:/ / doi.org/ 10.5185/ amp.2017/ 805

Copyright: VBRI Press

Publisher URL: https:// www.vbripress.com 


\title{
Production system and material efficiency challenges for large scale introduction of complex materials
}

\author{
Martin Kurdve ${ }^{1,2^{\star}}$, Fredrik Henriksson ${ }^{3}$, Magnus Wiktorsson ${ }^{2}$, Patrick Denzler ${ }^{2}$, Mats Zackrisson ${ }^{1}$, \\ Marcus Bjelkemyr ${ }^{2}$
}

${ }^{1}$ Swerea IVF, Mölndal, 43153, Sweden

${ }^{2}$ Mälardalen University, Eskilstuna, 63105, Sweden

${ }^{3}$ Linköping University, Linköping, 58183, Sweden

*Corresponding author: Tel: (+46) 317066000; E-mail: Martin.Kurdve@Swerea.se

Received: 14 December 2016, Revised: 11 June 2017 and Accepted: 26 June 2017

DOI: $10.5185 / \mathrm{amp} .2017 / 805$

www.vbripress.com/amp

\begin{abstract}
This paper links production system research to advanced material research for the vehicle industry. Facilitated by need for reduction of fuel use, the automotive industry is pushing a radical change from using steel structures to new mixed materials structures. In production systems optimised for steel, the changes will affect productivity and material efficiency. Four industrial case studies focusing on production economy and productivity give implications of production technology demands on the material selection regarding new joining techniques and additive or forming methods which has to be investigated when considering new materials. Material efficiency analysis shows that minimising spill in production operations and regulatory demand of recycling need to be considered in material development, which implies both design for disassembly, advanced separation processes and use of recycled raw materials. To be successful in new material introduction, new information flows and knowledge sharing moving from operations and manufacturing development to materials development and design are needed. The material developers could use axiomatic design strategies to structure the production system demands on the materials. State of the art lightweight producers in vehicle and automotive industry are likely early adopters to advanced lightweight structures with need of information flows between material development and operations. Copyright $\odot 2017$ VBRI Press.
\end{abstract}

Keywords: Mixed materials, material efficiency, light weight products, materials development, production system.

\section{Introduction}

The materials used to manufacture products are increasing in numbers and how advanced they are. Therefor there is need for more innovation and research of advanced materials, its processes and manufacturing technologies [1]. Advanced manufacturing technologies in turn give additional requirements on the development of new materials. However, the development needs to be specified for different industrial sectors and products [1].

Facilitated by need for more sustainable products and reduction of fuel use to combat climate change, the automotive and vehicle industry introduce advanced lightweight structural materials. This trend is pushing a radical change from using mainly steel to using a broad range of new mixed materials in a larger scale. The body in itself, using traditional material like steel, may account for $40 \%$ of the total weight of the vehicle [1]] [2] and with lighter body, further downsizing of driveline and engine is possible [3]. The broad challenges in automotive product design are to a large extent known and includes introduction of light weight structures, new and/or hybrid driveline technologies and recycling of materials [4]. Research on advanced lightweight material is naturally focussed on technical challenges in meeting product demands, e.g. the combustion engine heat resistance in Aluminium alloys for cast engine blocks [5], or the production of the material itself, e.g. production of magnesium based sheet metals [6]. However, the needs of detailed research that take the automotive production infrastructure into account can still be further specified.

In the automotive manufacturing systems, usually optimised for steel, the material changes will affect productivity and material efficiency and sustainability of the supply chain [7]. In automotive industry with manufacturing of vehicles in a Mixed-Model Line (MML) [8,9] different models of vehicles are produced after each other in a balanced flow. This means that models with new types of material has to be produced in the same line as the older steel structured vehicles as shown in Fig. $\mathbf{1}$ below. The new materials will thus be introduced in a "brown field", changes of an existing system, rather than a "green field" situation where a completely new manufacturing system is set up [7]. A typical 
automotive manufacturing line can be divided into three consecutive lines, the body shop with structure forming and joining e.g. steel plate press and welding, the paint shop with surface treatment, e.g. electro-coating and paint shop, and the assembly line where other parts and structures are assembled with the vehicle body [10]. Introduction of new structural materials will thus need to take into account the sequence of processing and whether the material is part of the body or assembled onto it. In addition, recycling of new material combinations is in the automotive industry a prerequisite for enabling weight reduction through mixed materials because car manufacturers in Europe from 2015 according to law must be able to demonstrate that at least $95 \%$ of the car's weight can be recycled or reused when the car is scrapped. Thus, the recycling potential, which is dependent of the materials used, the joining technique, surface treatment etcetera, must be assessed at an early stage in any vehicle light-weighting project.

\section{Todays structures}

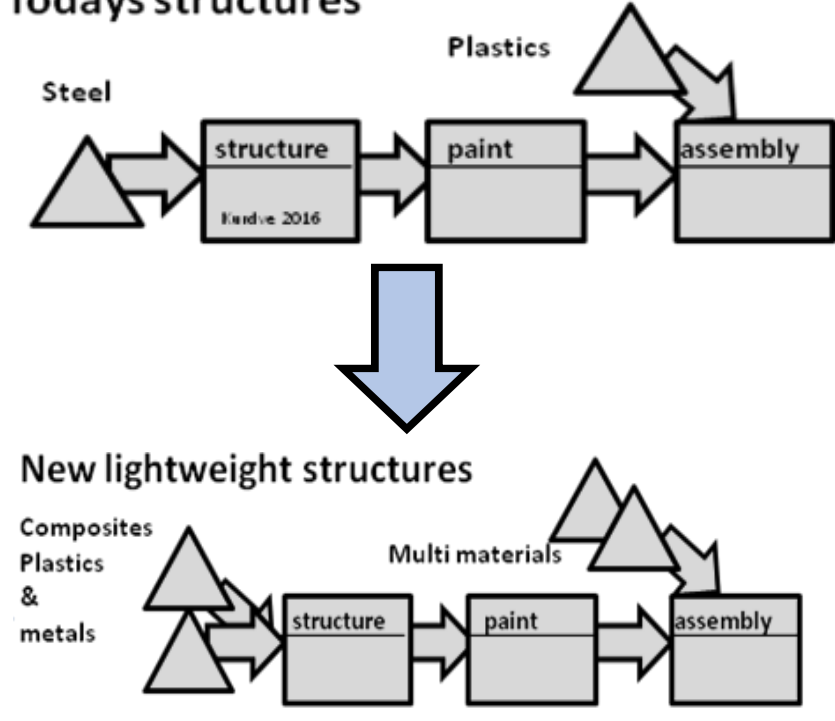

Fig. 1. New materials are introduced into existing manufacturing system meaning the materials are introduced to other materials processes.

Materials that are researched and introduced in the automotive industry to make the cars lighter are fibre reinforced plastics, e.g. bio-fibre filled polymers or carbon fibre reinforced polymers (CFRP) [11], and light weight metals, e.g. aluminium and magnesium [12], but also high strength steel [13], e.g. boron steel, which have the same or higher density but can give a slimmer design. Although most material research takes into account both the product properties needed and manufacturability of the material i.e. sheet metal production or moulding properties, few (if any) take into account the productivity and lead time demands of an automotive MML. From a material development perspective, several proposed materials, which seems to be promising for the functionality of the product, may be discarded or delayed in introduction due to incompatibility with the existing automotive production system. This paper aims to investigate these "showstoppers" and introduce what parameters of the process and of the materials that need to be known early on [14] in order to develop the new materials needed in the industry.

Besides product quality and cost, also the time for development is of major importance [15] as is the knowledge development i.e. knowledge about the material attributes. It is important to have time to develop the knowledge of the new materials in the application they will be used. Material research and material design occurs in the early concept phases of product and manufacturing design process. In these phases, the number of solution options are many and the evaluation criteria are not fixed [16]. Research on material implementation thus need to study the communication and information on requirements between production development, design and material development.

\section{Problematizing}

The academic approaches used in early material design phases are in most cases based on a green-field design process rather than the most common "brown field" situation where new material is incorporated in an existing product in an existing manufacturing system both limited with regards to investments and redesign; depending on existing equipment and facilities, legacy systems and demands on adaptability and sustainability [17]. Manufacturing involvement in the early phases of design is low [18] and therefore considerations of the manufacturing system is limited. Material development is done even before product design, and is thus often done without considering the automotive manufacturing system. In order to study the complex relations between product requirements, production process requirement and production system requirements, two research questions were formulated, guiding the research studies:

-What production system challenges incur by introduction of new complex materials in the automotive industry?

-What production related parameters are critical to facilitate quicker industrialisation of new material products in vehicle industry?

\section{Experimental}

\section{Materials}

Three large industrial companies have participated in the project with four different studies, case A, B, C and D. All of them introduces new (but not necessarily novel) materials into existing production processes and investigates feasibility, risks and opportunities in the introduction process. In Case A replacement of injection moulded PP with different mixtures of flax and polypropylene were investigated.

In case B and C, replacement of cold rolled steel plate with fibre reinforced plastics or rolled aluminium plate was studied. In Case D substitution of high strength steel with carbon reinforced composites were studied.

\section{Characterizations}

The manufacturing processes investigated in this research includes forming, joining and surface treatment of the 
materials involved but not the extraction process of the material itself.

Literature studies together with case studies using simulation and calculation were complemented by cross-case workshops using focus group discussions with experts from academia and industry.

Case A analysed two change options of producing the structure for interior parts that are joined with the car in the assembly line, and investigates opportunities and risks regarding productivity. Two scenarios of introducing biofibre into a set of polypropylene parts were investigated. The different ways of introducing fibre reinforcement in the thermoplastics forming process were investigated and analysed with regards to lead time and line stability. The computations were based on data collected on two-line walks in December 2014 and cycle time data from the manufacturing system. Value stream maps and a discrete event simulation model for the existing as well as for the two different alternatives using process simulator were used in analysis of the line stability. The capability data for the future scenarios were extrapolated using performance improvement from other published empirical research on injection moulding $[19,20,21]$. The general results are discussed also for the situation where parts would have to go through the body and paint shop processes.

Case B and C were both case studies at the same company, where lightweight material were introduced in different parts of the steel body structure. The initial aim to introduce a type of fibre reinforced plastics was abandoned, due to the critical combined issues of forming, joining and surface treatment in a mixed model line, and a light weight metal prospect was studied in the rest of the studies. The current multi material solutions was made to research the purpose of lightweight design and possibilities for mass reduction approaches. Subsequently, an industry overview was performed to investigate current multi material solutions. In parallel, a general process model for vehicle car bodies was created from empirical findings.

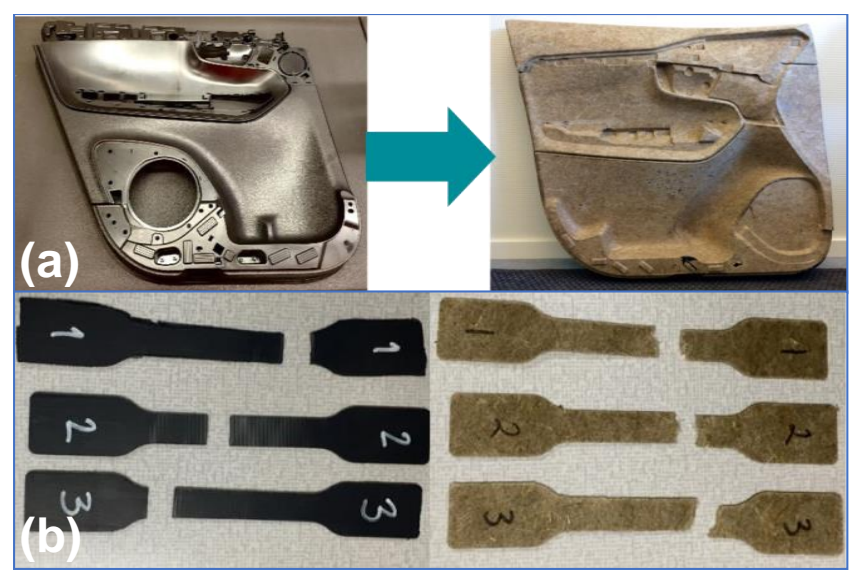

Fig. 2. (a): Product in Case A and (b) test of product properties [19].

In case $\mathrm{D}$, introduction of a carbon reinforcement of a high strength material in the main structure of a vehicle were considered, and how a mixed structure can handle paint shop processes, especially heating. A preliminary simulation model was reviewed using typical data on temperatures and process times. In this paper, mainly the knowledge needed for modelling the system was considered.

Finally, five cross-case focus group discussions were used to compare outcome and methods between the cases and with experience from other research projects. The focus group discussions were used to analyse the overall results and answer what production related parameters are critical to facilitate quicker industrialisation of new material products in vehicle industry?

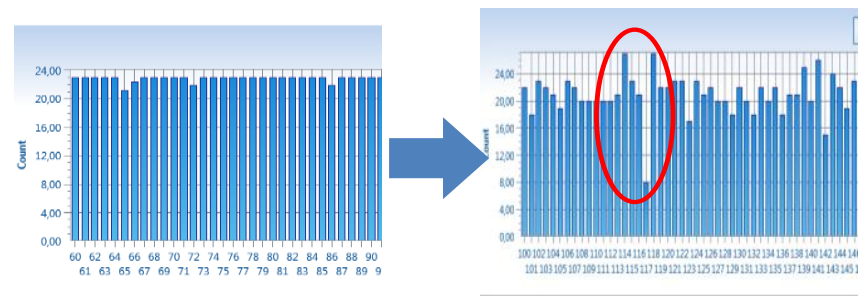

Fig. 3. Simulated delivery from the process at current state and case A first option - future state.

\section{Results and discussion}

Results of case A, fibre reinforced polypropylene in assembled parts

Two scenarios were used to introduce bio-fibre into a set of polypropylene parts. One using preformed sheets of fibre that are set into the mould and polypropylene is injected while the other method is using polypropylene (PP) with bio-fibre mixed into the granulates. The first scenario (Fig. 2a) was tested with regards to product demand: heat resistance, fire resistance, moisture resistance, smell and tensile strength (Fig. 2b) in a student project [19]. The existing PP Injection Moulder (IM) was the bottleneck of the process with low availability ( $80 \%$ ) and long setup time (40 minutes) leading to large batch sizes and thus long lead time for the parts [22]. The first option investigated by the case company was to install a new IM with inserts of preformed mats and fully automated offloading into the laminator. Full automation was a necessary man-time cost saving to pay off the equipment investment. The internal goal was to reduce weight as close to $50 \%$ as possible while still using low cost materials. Using as high as $50 \%$ bio-fibre (density $1400 \mathrm{~kg} / \mathrm{m}^{3}$ ) mixed with polypropylene (PP) (density $900 \mathrm{~kg} / \mathrm{m} 3$ ) was tested in lab scale [19] with non-satisfactory results. At a too high fibre content $(>50 \%)$ the strength of the material is reduced and thus give no weight reduction. According to literature the optimal bio-fibre mix of PP for conventional IM technology is between $20 \%$ [20] and $40 \%$ [21]. With an optimal mix, the material can reach double the strength compared to pure PP and thus the weight reduction may be up to $44 \%$ reduction of weight. Although the average capacity would be fairly satisfactory (Fig. 4), the simulation study showed, that going from a stable process, the first option gave an unstable process that would not deliver the required number of products each hour (Fig. 3). The prospected equipment would suffer from large sensitivity to disturbance and thus require a 
maintenance cost increase to keep the high requirement on availability. In addition, it was unclear if the material would be recyclable as process spill or at end-of-life of the car. The process instability was perceived as a "showstopper" and it was chosen not to proceed with this process.

A second option based on incremental improvement of existing line was investigated. The PP granulates would after adjusting the IM, do an incremental increase of fibre. Up to $30 \%$ fibre within the granulate can be used with only adjusting the IM machine [23]. At least 20\% fibre in the PP can be reached according to [20], which give a $45 \%$ increase of strength or consequently a $30 \%$ reduction of volume or $25 \%$ reduction of weight. This change requires minimum additional investment in the IM although it requires a more expensive (in cost per weight) raw material. In the second option, instead of investing in new processes, time is invested in adjusting and improving the IM. Improvements of $50 \%$ in setup-times and reducing downtimes by $50 \%$ by working with TPM, operator maintenance and condition based maintenance can be expected $[\mathbf{2 4}, \mathbf{2 5}, \mathbf{2 6}, \mathbf{2 7}]$. The simulation showed more stable behaviour of the process (compared to the first option), capacity increase and substantial reduction in batch size and thus lead time (Fig. 4). One unanswered question was if the parts with fibre would solidify as fast as pure PP. Research is also needed on recyclability of the PP fibre mix. How much the fibre will lose in strength during recycling loops is one such question. Although, loss of product properties during recycling is not a "showstopper" in a regulatory sense, it may give negative effects on the overall global warming from the lifecycle of the car. Both solution need to integrate joining with polyurethane foam and TPO-foil.

\begin{tabular}{|c|c|c|c|c|}
\hline Parameters & & Baseline & $\begin{array}{l}\text { Preformed } \\
\text { fibre inserts }\end{array}$ & $\begin{array}{l}\text { Granulates } \\
\text { with fibre }\end{array}$ \\
\hline Need & sets $/ h$ & 23 & 23 & 23 \\
\hline Takt time / parts & $\min$ & 0,65 & 0,65 & 0,65 \\
\hline Capacity & $\# / \min$ & 2 & 2 & 2 \\
\hline Cycle time & $\min$ & 1 & $0,8-1$ & 1 \\
\hline Availability & $\%$ & 80,5 & $90-98$ & 90 \\
\hline Setup time & $\min$ & 40 & 5 & 20 \\
\hline Batch size result & $\#$ & 600 & $40-60$ & 90 \\
\hline Static lead time & hours & 13,1 & 1,16 & 2,03 \\
\hline Calculated max capacity & sets $/ h$ & 22,92 & 27,9 & 24,7 \\
\hline Material weight & $\%$ & $100 \%$ & $61 \%$ & $75 \%$ \\
\hline Dynamic Capacity & sets $/ h$ & 22,89 & 21,02 & 23,5 \\
\hline Simulated Avg. lead time & hours & 14,72 & 1,60 & 1,39 \\
\hline
\end{tabular}

Fig. 4. Results from bottleneck calculation, value stream mapping and simulation.

The study results demonstrate a typical example that it may be advantageous to increase research on material and process solutions where current infrastructure can be largely unchanged and where the introduced material behave as much as possible as the old material in the production process and in use. The results are in line with Nunes and Bennet [7] who show that automotive industry in general is not ready for radical improvements.

Result of case B, light weighting of car body side with aluminium sheet
The case investigated production system consequences when changing steel sheet into light weight material (especially aluminium sheet metal) into a section of the car body. The current state of the production line was modelled in the discrete event simulation software ExtendSim. Within the production line, two stations were identified as critical with regards to material change: spot welding and laser welding. The identified stations were located after each other in the middle of the car body welding line (Fig. 5 a). The stations had different cycle times, and one product was buffered by a first in first out (FIFO) buffer between the two stations.

The future process had to be severely different to the original. The aluminium sheet could not be welded directly on the steel frame. Instead an adhesive joining was investigated, applied by two robots in the future state (Fig. 5 b), instead of the two serial stations in the current state. This challenged the cycle time optimization (in the minute range) in that station. The introduction of an adhesive was also challenged by the temperatures, at 180 degrees, in the paint shop oven, that the adhesives used to fit the aluminium to steel needed to handle. Other issues with the different adhesives considered were health concerns for the workers, curing time and fixation as well as vibration during transport to the next station.

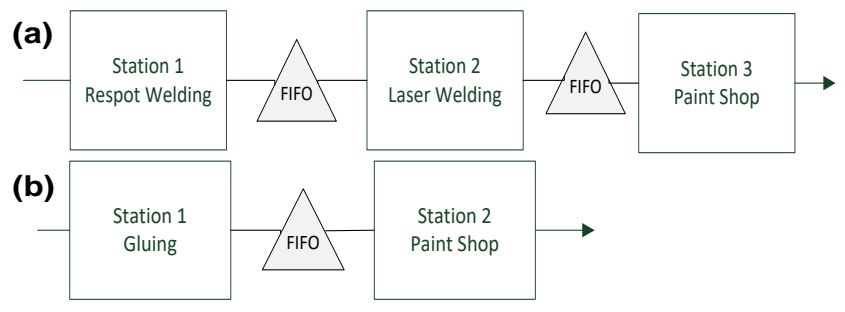

Fig. 5. (a) Current state) and (b) future state, of the production stations in focus for Case B.

To be successful in material and adhesive development, new information flows and knowledge sharing going from operations and manufacturing development to materials development and design were needed [28]. Process capability and target cycle times of current and future operations needed to be known or accurately estimated with data from machine suppliers, manufacturing research and/or state of the art benchmarks. It was important to know, not only the current manufacturing process, but also the upcoming production system changes in order to know when different materials could be introduced in different parts of the product as well as to know when different material design criteria are valid for the product. New materials in a loose part like the bumper could have been easier to introduce into the existing production system while changing material in an integrated body structure, like the roof or the floor, needed a timely consideration of production system change plans. For each structure, the material-product-process relation needed to be established.

Results of case C, light weighting of car roof with aluminium sheet metal 
The setup of the case project followed the methodology described by Ulrich and Eppinger [15]. The project followed activities from project initiation until selected product concept. The project was set up as a breadth-first analysis project to mimic how product development processes are often described in literature, as opposed to a depth-first analysis which evaluates all or nearly all possible concepts before selecting concept and proceeding into detailed design. A brainstorming and two sessions of pairwise comparison gave the five most important requirements, which were redefined into three main criteria: A fast, energy efficient manufacturing process, a strong material with low costs and a lightweight but strong component. The result from case $\mathrm{C}$ showed a significant challenge in following traditional product development processes when introducing new materials without redesigning the whole product. In the development process, the aim to avoid arbitrary design decisions (seen as not adding design knowledge) and the aim to minimize work on later not selected design concepts (translated into project cost) clashed. In this case, the selection of joining technology became a stumbling point since selection of joining technology is highly dependent on detailed design and reinforcements.

Table 1. Classification of different joining technologies.

\begin{tabular}{ll}
\hline Example of joining technology & Joining process type \\
\hline Welding & Thermal \\
Nut-and-bolt & Mechanical \\
Riveting & Mechanical \\
Adhesive & Chemical \\
Snap-joints & Mechanical \\
Brazing & Thermal \\
\hline
\end{tabular}

Material changes usually lead to the need for investigating new additive or forming methods and new joining technologies [29], due to differences in material properties such as surface hardness, chemical resistance and service temperature. For advanced composite materials, the forming process need to be adjusted. In the investigated cases, the introduced materials bring in either that a reinforcement need to be introduced into the forming (i.e. introducing fibre reinforcement thermoplastics moulding) or a new similar material need to be formed with new tools (aluminium forming as replacement from steel). In order to design the forming process, it is required to have thorough knowledge of the materials deformation attributes (plasticity, elasticity etc.) and how these change with pressure and temperature. It is also important to have a thorough knowledge of hardening or curing properties, not just the time to a set stiffness/hardness but also the behaviour through the hardening/curing process. With new and novel materials, there may also be need of substantial research on the joining with other materials, i.e. welding of the structure needs to be replaced with other joining technology. It is thus important to have a good knowledge of the status of joining technology research as well as the technology readiness level of different technologies. This is further emphasized by the classification of different joining technologies into mechanical, thermal, chemical and hybrid joining process types (Table 1) [30]. The classification may be used if there is a good knowledge of the new materials regarding the joining processes, with thermal joining being the most established in automotive body manufacturing. Thermal joining is often the most time-efficient (and adds negligible mass to create the bond), but is also the most material-sensitive technology. Welding, riveting and adhesive joining are in general not considered beneficial for the fragmentation based recycling used in the automotive industry [31]. In addition, lean and six- sigma manufacturing demands, require joining technologies to be standardized with high process capability and as simple as possible. Similar requirements are set by safety standards in the automotive industry. Introduction of new joining in mass production of vehicles, considers learning of the new method and its applicability in other (future) joining operation changes. The joining may need to handle a precipitation test on line which give requirement on hardening/curing time, or downstream assembly processes that set requirements on hardening/curing time [30]. Also, the noise and vibration analysis showed that there might be need of extra anti-acoustic material (e.g. antiflutter, acoustic foam) to reduce noise which means saving less weight than planned.

Table 2. Test specimen object temperature.

\begin{tabular}{cccc}
\hline Step & Temp [C] & time [min] & slope [C/min] \\
$\mathbf{1}$ & $20-140$ & 5 & 24 \\
$\mathbf{2}$ & $140-180$ & 3,5 & 10 \\
$\mathbf{3}$ & $180-140$ & 2,5 & -14 \\
$\mathbf{4}$ & $140-90$ & 2 & -25 \\
$\mathbf{5}$ & $90-20$ & $>5$ & cooling \\
\hline
\end{tabular}

Results of case D, paint shop requirements on material and joining solutions

The structure material will be exposed to sunlight, precipitation as well as warm and cold temperatures (from -50 degrees to +120 degrees). Usually this adds to the requirements regarding surface treatment and paint (also for appearance reasons). The main issues are; does the paint stick (adhesive properties in typical steel electro-coating processes and paint) and the effects, short term and long term from heating the material and its joining in the paint shop oven. Here it is important that the material elongation in the design does not differ from the remaining frame when going through ovens. Simulation modelling of thermal extraction is dependent on thermal properties of the different materials involved, the design and the oven geometry as well as time aspects. Table 2 shows typical temperatures and time at each temperature the structure material will be submitted to. It is important to have a good knowledge of the material elongation, strength and the joining performance in the whole temperature range (product use and manufacturing process) from -50 to +180 degrees. Equally important for the manufacturing process requirement is the time issues e.g. how long time does it take to cure the paint, will the material be heated up in the time frame or not etc.

\section{Cross case discussion}


The cross-case analysis was performed through five focus group discussions (I-V), as mentioned in the method section. When introducing new materials in the vehicle industry, it is clear in all four cases that the use-phase give requirements on the material and joints to withstand rain, sun, warm and cold temperatures as well as having demands on deformation in case of a crash (I). However, during manufacturing the material may suffer more extreme conditions with regards to temperature and chemical withstand. When producing large structures, the common operation sequence in vehicle industry is forming different parts, joining them together to a structure and then surface treatment / painting. Finally, smaller component structures (also formed, joined and surface treated/painted) are assembled with individual types of joining. An additional demand is that the material needs to be material recycled at end-of-life of the vehicle which limits the choice of joining technologies (V). The production system stability is highly dependent on time and sequencing (II). This means that joining method alternatives should be thoroughly researched before starting a change project (III-IV). For example, the time for curing of adhesives should be known before decision making. For material and adhesive developers, it is crucial to deliver data on how the material will behave in the production conditions and with different joining technologies.

Previous industrial case studies of material efficiency in the Swedish vehicle industry as well as case A show that challenges of minimizing material spill in production operations and recycling demands need to be considered in material development $[32,33]$. The life cycle environmental impact from extraction and processing of raw materials is increasingly important with new lightweight materials and new driveline technologies (V). Therefore, material efficiency both by minimizing production spill and ensuring efficient recyclability of the material is crucial to minimise total environmental impact of vehicles. The sourcing demands are increasingly important. Advancement of spill minimization involves knowledge of forming processes that will be used and their process capabilities for each material, e.g. will there be moulding, pressing cutting or grinding involved (II, V). In addition, if the material gives more noise than previous material it may need extra add-on noise reduction material (e.g. foam) into the product, reducing the weight gain. The recycling demands of the products implies both design for disassembly and more advanced separation processes in the recycling end of the production system. Recyclability efficiency is closely related to selection of joining and availability of disjoining operations in existing recycling processes. When it comes to total climate effect of a material it should be possible to start with that investigation early in a project in order to do sourcing option investigations and give supplier requirements early to make sure that e.g. recycled material is available.

Automotive production lines are complex with a large number of stations with a relatively short takt time, typically in the minute range. This adds another dimension of complexity in terms of productivity and lead time demands of an automotive production line, in addition to the product properties needed and manufacturability of the material.
When introducing new materials in an existing line the challenge is to include the new material and process in the flow together with old models made of steel. The industrial case studies of production economy and productivity give further implications of production technology demands on the material selection [22]. All these implications will affect the development and introduction of new materials. The result of study A concluded that value stream mapping is a feasible way to understand the manufacturing system demands. Although study B could not conclude process validation with discrete event simulation in early phases of product and manufacturing design, it did show the benefits for concept experimentation, and study A also showed some usefulness in risk minimization. For the material developer, it is important also to consider that introduction of new materials do not only give rise to increased costs in manufacturing, it may also give opportunities to cut costs. The materials developers could use axiomatic design strategies to structure the production system demands on the materials. State of the art lightweight producers in vehicle and automotive industry are most likely the early adopters to the production system and can develop new use of information flows between material development and operations (IV, V).

\section{Summarizing challenges and critical parameters for large scale introduction of complex materials}

Based on cases and cross-case focus group workshops, findings are summarized for the development and industrialisation project as a whole, as well as specific critical processes and parameters for the three main processes of an automotive line (Fig. 6).

For the development and industrialisation project as a whole, it is essential to identify showstoppers: When developing, and designing lightweight material for large scale production of vehicles, it is advisable to acknowledge certain features that will be "showstoppers" in the industrialization phase if not handled correctly. For instance: Can it be painted with the same system as other parts/structures? How does the material change when heated/cooled-compared to the other materials in the vehicle? In addition, it is critical to balance product requirements (design, strength etc.), production process requirement (physical, chemical) and production system requirements (cost, time, knowledge/risk).

For the body shop with structure forming and joining, the material behaviour is critical: New materials are expected to be lighter and/or stronger than steel but in as many as possible ways else similar to steel (temperature, elongation, surface etc). It is advisable to have a thorough knowledge of the behaviour of steel when developing material for the vehicle industry. Joining is a key process for mixed material products. Key questions are: What materials will this material be joined to? What are their features and what requirements doing they give to the joining? Flexibility torsion, stiffness etc. that the join needs to withstand. Unjoining: if the joined parts differ in material, the demand in vehicle industry is to recycle each material, i.e. separation needs to be possible. Critical parameters to consider in the body shop is temperature, pressure, curing time and cycle times. 
In the paint shop with surface treatment, steel (even stainless steel) need to be rust protected. This is often done by electrophoretic deposition and painting. Curing is usually done in an oven. It is important to know how the material behaves together with e.g. steel within the temperature range. Aspects to consider are: Material elongation, joint-flexibility and acceptability of the surface treatment. Critical parameters to consider in the paint shop is temperature, curing time and effect on joints.

In the assembly line where other parts and structures are assembled with the vehicle body, noise and vibration characteristics of the material in the desired design should be evaluated. Design will give demands depending on marketing etc. Safety issues will give special demands of different parts of the vehicle structure (e.g. the cage around driver and passengers need to be strong and rigid, while other areas might be designed to be flexible). In addition, a vehicle need to withstand temperatures from $-50-120{ }^{\circ} \mathrm{C}$, rain and moisture, wind and sunlight. The technical life cannot be less than ten years for the structure. Critical parameters to consider in the assembly shop is sequence, standardisation, joint types and cycle times.

Fig. 6. Critical parameters in vehicle production processes.

\begin{tabular}{lll}
\hline Process & Critical processes & Critical parameters \\
\hline Structure & Forming, Joining & $\begin{array}{l}\text { Temperature, pressure, } \\
\text { curing time, cycle times } \\
\text { Paint shop }\end{array}$ \\
Assembly & $\begin{array}{l}\text { Surface treatment, } \\
\text { painting, heating } \\
\text { Joining }\end{array}$ & $\begin{array}{l}\text { Temperature, curing time, } \\
\text { effect on joints, } \\
\text { Sequence, } \\
\text { standardisation, joint } \\
\text { types, cycle times }\end{array}$ \\
\hline
\end{tabular}

\section{Conclusion}

This research has studied the complex relations between product requirements, production process requirement and production system requirements, during large scale introduction of new complex materials in automotive manufacturing. It focuses on incurred production system challenges as well as critical production related parameters facilitating quicker industrialization of new material products. Four cases were studied, in addition to literature studies and focus groups. Based on cases and cross-case focus group workshops, findings are summarized for the development and industrialisation project as a whole, as well as specific critical processes and parameters for the three main processes of an automotive line: body shop, paint shop and assembly line. Critical parameters for material and joints include that they need to: withstand process temperatures, curing times for joints and paint, elongation of the material compared to e.g. steel and recyclability etc. It is possible to introduce materials that do not fit these demands, but it will take longer time before the market is ready to use them. A major implication is that there is need for further joint research with material researchers and production system researchers such as [33].

\section{Acknowledgements}

The authors wish to thank all students from LIU and MDH taking part in the specific case studies. The contribution and funding originates from the projects; CIMMREC, funded by Mistra, and Large-scale production of mixed material products, funded by Vinoba Production 2030. Part of the research is performed within the XPRES program at MDH.

\section{Author's contributions}

Project management: MK; Case A: MK with input from MB and MZ; Case B: MW, PD. Case C: FH, MZ. Case D review: MK; Cross-Case analysis: MK, FH, MW, PD, MZ; Wrote the paper: MK, FH, MW, MZ, MB (xx, xy, $\mathrm{yz}$ are the initials of authors). Authors have no competing financial interests.

\section{References}

1. Featherston, C. R.; O'Sullivan, E. A review of international public-sector strategies and roadmaps: A case study in advanced materials. A report for the Government Office of Science \& the Department for Business, Innovation \& Skills; Centre Sci. Technol.Innov., Inst. Manuf. Univ. Cambridge, UK. 2014

2. L. W. Cheah Cars on a Diet: The Material and Energy Impacts of Passenger Vehicle Weight Reduction in the U.S. Massachusetts Inst.Technol.Eng Syst. Div. US 2010.

DOI: http://hdl.handle.net/1721.1/62760

3. Tempelman E. Transp. Res. Part D Transp. Environ. 2011, 16, 7, pp. 479.

DOI: $10.1016 / j . \operatorname{trd} .2011 .05 .007$

4. Mcauley, J. W. Environ. Sci. Technol. 2003, 37, 23, pp. 5414-5416. DOI: $10.1021 / \mathrm{es} 030521$

5. Awe, S.; Seifiddine,S.; Jarfors, A.; Dahle, A. Eur. Adv. Mater. Congr. Proc. Abstr. book, 2016, 443.

DOI: $10.5185 /$ eamc2016,

6. Park J-J. Eur. Adv. Mater. Congr. Proc. Abstr. book, 2016, pp. 445-446. DOI: $10.5185 /$ eamc2016

7. Nunes, B.; Bennett, D. Benchmarking: Int. J., 2010, 17(3), pp. 396-420. DOI: $10.1108 / 14635771011049362$

8. Thomopoulos, N. T. Manage. Sci., 1967, 14, 2, B-59. DOI: $10.1287 / \mathrm{mnsc} .14 .2 .659$

9. Boysen, N.; Fliedner, M.; \& Scholl, A. Eur. J. of Oper. Res. 2009, 192, 2, pp. 349.

DOI: $10.1016 /$ j.ejor.2007.09.013

10. Gernuks, M.; Buchgeister, J.; Schebek, L.; J. Cleaner Prod. 2007, 15, 11, pp. 1063.

DOI: $10.1016 /$ j.jclepro.2006.06.003

11. Pimenta, S.; Pinho, S. T. Waste manage. 2011, 31(2), pp. 378.

DOI: $10.1016 /$ j.wasman.2010.09.019

12. Kulekci, M. K.; Int. J, Adv. Manuf. Tech.., 2008, 39(9-10), pp. 851. DOI: $10.1007 / \mathrm{s} 00170-007-1279-2$

13. Tisza, M. Int. J. Microstruct. Mater. Prop. 2013, 8(1/2), pp. 125. DOI: $10.1504 / \mathrm{IJMMP} .2013 .052651$

14. DIRECTIVE 2000/53/EC, Off. J. Eur. Communities: Legis L 269/34 pp. $1-15,2000$.

DOI: http://eur-lex.europa.eu/legal-content/EN/TXT/? uri=URISERV:121225

15. Ulrich K. T.; Eppinger, S. D. Product design and development, McGraw-Hill, Singapore, 2008

16. Slack N; Chambers S; Harland C; Harrison A; Johnston R; Operations Management. Second Edition. Pitman Publishing. London, 1998

17. Wiktorsson, M.; Consideration of Legacy Structures enabling a Double Helix Development of Production Systems and Products. In Technology and Manufacturing Process Selection: the Product Life Cycle Perspective.; E. Henriques, P. Peças and A. Silva. (Eds.) Springer. 2014 DOI: $10.1007 / 978-1-4471-5544-7 \_2$

18. Ettlie, J E. Early manufacturing involvement in new product development, in Proc. 1995 IEEE Annu. Int. Eng. Manage. Conf. Singapore, pp. 104, 1995.

DOI: $10.1109 /$ IEMC.1995.523917

19. Marberg, A.; Östergren, R.; A study of flax materials for new door panels (in Swed.), Diploma thesis nr: 130/2015 CPL ID: 218777 Chalmers Univ. Technol. Göteborg 2015

DOI:http://publications.lib.chalmers.se/records/fulltext/218777/218777. pdf

20. Mattsson, J.; Technical Analysis of Flax Fiber Reinforced Polypropylene: Prerequisites for Processing and Recycling. M.Sc. 
Thesis in Chem. Eng. Faculty of Health, Sci. Technol. Karlstad Univ., Sweden 2014.

DOI:http://urn.kb.se/resolve?urn=urn:nbn:se:kau:diva-32352

21. Bledzki, A. K.; Mamun, A. A.; Faruk, O.; Express Polym. Lett. 2007, 1, 11, pp. 755-762.

DOI: $10.3144 /$ expresspolymlett.2007.104

22. Kurdve, M.; Sjögren, P.; Gåsvaer, D.; Wiktorsson, M. Procedia CIRP, 26th CIRP Des. Conf. 2016, 50, pp. 160-165

DOI: $10.1016 /$ j.procir.2016.04.137

23. Gulbarga, M. A.; Burli, S. B. Int. J. Sci. Res. Publ. ISSN 2250-3153 2013, 3,8 .

DOI: http://www.ijsrp.org/research-paper-0813.php?rp=P201665

24. McIntosh, R. I.; Culley, S. J.; Mileham, A. R.; Owen, G. W. Int. J. Prod. Res. 2000 38, 11, pp. 2377-2395.

DOI: $10.1080 / 00207540050031823$

25. McIntosh R.I.; S.J. Culle; A.R. Mileham; G.W. Owen; Int. J. Prod. Econ. 200173.2 pp.153-163. DOI: $10.1016 / \mathrm{S} 0925-5273(00) 00170-5$

26. Salonen, A.; Bengtsson, M.; J. Qual. Maint. Eng. 2011 17, 4, pp. 337 350 .

DOI: $10.1108 / 13552511111180168$

27. Karasu, M. K.; Cakmakci, M.; Cakiroglu, M. B.; Ayva, E.; DemirelOrtabas, N. Meas. 2014 47, pp. 741-748.

DOI: $10.1016 /$ j.measurement.2013.09.035

28. Denzler, P.; Wiktorsson, M. Procedia CIRP, 26th CIRP Des. Conf. 2016, 50, pp. 270-274.

DOI: $10.1016 /$ j.procir.2016.05.033

29. Henriksson, F.; Johansen, K. Procedia CIRP, 26th CIRP Des. Conf. 2016, 50, pp. 683-688.

DOI: $10.1016 /$ j.procir.2016.05.028

30. Henriksson F.; Johansen, K. SAE Tech. Paper 2016-01-1332, USA, 2016

DOI: $10.4271 / 2016-01-1332$

31. Gesing, A. JOM .2004, 56, 18 pp. 18-27 DOI: $10.1007 / \mathrm{s} 11837-004-0176-5$

32. Shahbazi, S.; Wiktorsson, M.; Kurdve, M.; Jönsson, C.; Bjelkemyr, M. J. Cleaner Prod. 2016, 127: 438-450.

DOI: $10.1016 /$ j.jclepro.2016.03.143

33. Rybicka, J.; Tiwari, A.; Alvarez Del Campo, P.; Howarth, J.; J. Cleaner Prod. 2015, 91, pp. 251-261.

DOI:10.1016/j.jclepro.2014.12.033

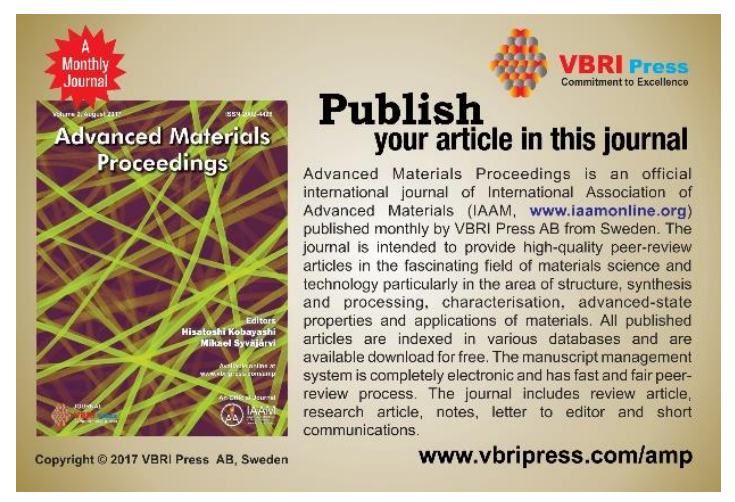

